E' relator da matéria o professor Dario Bittencourt, a quem concedo a palavra.

O SR. DARIO BITTENCOUR'T - (LE o Relatório e Parecer)

$O$ parecer que acabamos de ler, submetido à apreciação da nona Comissão foi integralmente subscrito.

O SR. PRESIDENTE - Em discussão as conclusões apresentadas pelo relator da Comissão.

O SR. GIRÃO BARROSO - Peço a palavra, Sr. Presidente.

O SR. PRESIDENTE - Tem a palavra o nobre Congressista.

O SR. GIRÃO BARROSO - O dr. Adherbal Freire é nosso colega de trabalho da Faculdade do Ceará e não pôde comparecer a êste Congresso para fazer pessoalmente a defesa de sua tese, em virtude de ter sido designado para acompanhar a nossa embaixada de acadêmicos à Europa. Incumbiu-me, entretanto, de ser também aqui o procurador de ausentes, de fazer a defesa do seu brilhante trabalho, tarefa que, entretanto, me dispenso de fazer, em vista do relatório do parecer muito bem elaborado pelo meu prezado colega Dario Bittencourt.

O SR. PRESIDENTE - Continuam em discussão as conclusões do relator.

Ninguém mais querendo fazer uso da palavra, está em votação. Os srs. Congressistas que não estiverem de acôrdo tenham a bondade de levantar-se. (Pausa).

Aprovado.

\section{INDICAÇÕES SÔBRE DIREITO TRABALHISTA}

\section{Félix Manuel Woelflin $e$ Alfredo J. Ruprecht}

Professôres catedráticos da Universidade de Rosário - República Argentina.

\section{POR CUANTO:}

- Dentro del Derecho Laboral no existe un sólo contrato, sino cantidad de ellos, con naturaleza propia y distinta, tales entre otros, los de "empleo privado", de "empleo público", de "aprendizaje". de "trabajo autónomo", etc.

- Unificar a contratos tan distintos dentro de una denominación única, no tendría razón de ser, y traería consigo funciones que es conveniente evitar.

- El llamado "contrato de trabajo", tiene su significado en la história del Derecho, pero carece de él en la actualidad, al mismo tihabstituto de la "locación de serviços", por el significado contrario a la dignidad humana que a esta última denominación se le atribuía, pedignidad humana que a esta ulima denomina carácter civil.

o su sustractum es el mismo y su origen debe ser precisa y no corresponder a mas de una institución.

POR ELIO EL CONGRESO JURIDICO CONMEMORATIVO DEL CINCUENTENARIO DE LA FUNDACION DE LA FACULTAD DE DERECHO DE RIO GRANDE. DEL SUD DECLARA:

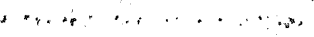

Oue la denominación "contrato de trabajo". és incorrecta, debiendo utilizarse la de "contratos laborales", cuando se refiere a los endo en in sentido amplio ó coneral $y$ la de "contrato" seguido con su denominación específica "de empleo privado", "de empleo público", "de trabajo autónomo", etc.), cuando se refiere a cada uno de ellos en particular. 


\section{RELATÓRIO E PARECER}

\section{Relator: MOZART VICTOR RUSSOMANO}

\section{RELATÓRIO:}

Os ilustres juristas argentinos prof. Alfredo J. Ruprecht e dr. Félix Manuel Woelflin, como colaboração a êste magno Congresso Jurídico, enviaram-nos rápida, sucinta "indicaçaco", constante de uma página datilografa, que se cifra na conclusão única e seguinte:

"La denominación "contrato de trabajo" es incor"recta, debiendo utilizarse la de "contratos laborales", "cuando se refiere a los contratos regidos por el Derecho "Laboral, en un sentido amplio ó general, y la de "con"trato" seguido con su denominación específica ("de em"pleo privado", "de empleo publico", "de trabajo autono"mo", etc.), cuando se refiere a cada uno de ellos en par"ticular".

\section{PARECER:}

Certa, rigorosamente, é a consideração básica de que, no Direito do Trabalho, existem CONTRATOS e não um único tipo de CONTRATO.

Suas modalidades são múltiplas e os tratadistas as classificam minuciosamente, sendo justa, aqui, a remissão que se faz ao brilhante esquema, quase completo, que RAMIREZ GRONDA, ilustre e consagrado patrício dos autores, em seu "Derecho del Trabajo", faz das diversas espécies do gênero CONTRATOS DE TRABALHO.

Aceitavel, portanto, a indicação, apenas com duas restrições, ditadas pelo espírito localista, a que o relator está prêso, do vernáculo e da lei brasileira.

I - A expressão idiomática "contratos laborales" (que só podemos traduzir por CONTRATOS TRABALHISTAS) não tem diferença gramatical, nem envolve, no nosso Direito, conteúdo jurídico diverso da locução "contratos de trabajo", i. é, CONTRATOS DE TRABALHO.

Aliás, para nós, brasileiros, já que os dois têrmos sã́o eqüivalentes é preferível a segunda expressão - porque a primeira impliça em estrangeirismo, tomada esta figura no seu exclusivo sentido técnicolingüístico.
II - No Direito Brasileiro, nãa se inclui, entre os contratos de trabalho, o AUTONOMO, apontado à guisa de exemplo pelos autorés da tese em exame. Isso porque há colisão entre o CONCEITO IURIDICO D OTRABALHO - que deve ser exetuado em gráu da subordinação hierárquica do empregado perante o empregador (art. 3. ${ }^{\circ}$, da Cons. das L. do Trab.) - e a liberdade de prestação do serviço, que caracteriza o trabalhador autônomo.

Êsses pequenos incidentes, aquêle de índole gramatical, e de índole específica do nosso Direito o segundo, não perturbam porém, o conjunto da indicação, que partiu de nomes que enriquecem a bibliografia jurídico-trabalhista em língua espanhola, ocupando lugar de realce entre os brilhantes escritores argentinos que trouxeram a êste conclave de estudiosos da lei e de cultores do Direito, a larga parcela de sua colaboração intelectual.

\section{DEBATES FM PLENÁRIO}

O SR. MÁRIO SEIXAS AURVALLE - (continuando, pois que ainda se encontrava na tribuna, de onde acabara de relatar a indicação anterior) - O professor Mozart Victor Russomano, da Faculdade de Direito de Pelotas, outorgou-me um mandato que muito me honra, qual o de fazer o relatório da tese que lhe foi apresentada \& que também é da autoria dos mesmos dois ilustres professôres da Universidade de Rosário.

Na proposição presente ao proféssor Mozart Victor Russomano, êstes ilustres juristas pedem que o Congresso Jurídico declare que a denominação "contrato de trabalho" é incorreta, devendo utilizarse a de "contratos laborales", quando se refere aos contratos regidos pelo Direito Laboral em sentido amplo ou geral, ou de "contrato laboral" em sentido ou denominação específica, quando se refere a cada um dêles em particular.

Significa dizer que a denominação "contrato de trabalho" deverá ser abolida, para ser aceita a de "contrato de direito laboral".

O professor Mozart Victor Russomano apresentou o relatório que vou me permitir ler ao douto Congresso: (Lê o Relatório).

Essas são as conclusões do professor Mozart Victor Russomano.

O SR. PRESIDENTE - Em discussão.

O SR. CAMILO MARTINS COSTA - Peço a palavra sr. Presidente.

O SR. PRESIDENTE - Tem a palavra o ilustre Congressista.

O SR .CAMILO MARTINS COSTA - Sr. Presidente. Desejaria que o ilustre realtor me esclarecesse um detalhe. No sentido de sưa proposição, o trabalho subordinado compreenderia o funcional, o prestado pelo funcionário público? 
O SR. MARIO SEIXAS AURVALLE - Não! Trabalho subordinado é apenas aquêle que é objeto do contrato de trabalho.

O SR. CAMILO MARTINS COSTA - Então, no sentido da proposição não se compreende o trabalho prestado ao Estado?

O SR. MARIO SEIXAS AURVALLE - Não se compreende. Classificamos o trabalho como autônomo...

O SR. CAMILO MARTINS COSTA - Sim! Autônomo, subordinado e prestado ao Estado. Êste está excluído da proposição.

O SR. MARIO SEIXAS AURVALLE - Exatamente.

O SR. SALOMÃO WEINBERG - Peço a palavra sr. Presidente.

O SR. PRESIDENTE - Tem a palavra o ilustre Congressista.

O SR. SALOMÃO WEINBERG - Gostaria de obter uma nova explicação do eminente relator.

O SR. MARIO SEIXAS AURVALLE - Perfeitamente.

O SR. SALOMÃO WEஹNBERG - Se não me engano, o relator entende que o trabalho subordinado compreende o trabalho doméstico e creio haver aí um equívoco. Gostaria de obter esclarecimentos do relator.

O SR. MARIO SEIXAS AURVALLE - Perfeitamente. Tenho o máximo prazer em esclarecer a V. Excia. Eu considero o trabalho doméstico como um trabalho subordinado, embora hoje ainda não esteja enquadrado na Legislação do Trabalho: Entendo, no entanto, que seria compatível com a nossa legislação, razão pela qual pregamos que, dentro do ramo do Direito do Trabalho, seja regulado todo trabalho subordinado, inclusive o trabalho doméstico e o do trabalhador rural.

O SR. SALOM̃̃O WEINBERG - Sr. Presidente. Concordo com - parecer do eminente sr. Relator, com uma pequena restrição, que desejo deixar esclarecida perante êsse colendo Congresso e me proponho deixar em separado, no voto perante a Comissão respectiva.

Entendo que deve ser subordinada ao atual Direito do Trabalho tôda matéria contratual que se revista de características eminentemente profissionais, e dentro destas características não entendo esteja o serviço doméstico, como outras relações que a própria natureza do serviço prestado poderiam pretender definições diferentes e não contidas no Direito do Trabalho. Fáltam-me, no momento, dados para indicar precisamente quais são êsses elementos, mas já encontrei em doutrinadores e mesmo em pareceres brilhantes, alguns dêsses elementos apontados, que dissociam os serviços domésticos do contrato de trabalho profissional.

Neste sentido é que eu expresso o meu voto.

O SR. MARIO SEIXAS AURVALLE - Peço a palavia, sr. Presidente.
O SR. PRESIDENTE - Tem a palavra o nobre relator.

O SR. MARIO SEIXAS AURVALLE - Desejava fazer um esclarecimento. Evidentemente, na nossa legislação está afastado do contrato de trabalho o serviço doméstico. Entende a maioria dos doutrinadores do Direito do Trabalho, que, como não se trate de trabalho com fins lucrativos e como esteja no âmbito do domínio familiar, êle não deve ser ali incluído; o trabalhador doméstico, conseqüentemente, não deve estar ao amparo da Legislação de Trabalho. Contra isso é que nos insurgimos na tese, porque entendemos que o Direito do Trabalho deve regular todo trabalho subordinado, seja êle o do trabalhador rural, seja o do trabalhador doméstico.

Esste o fundamento da proposição que encaminhei à Mesa, aliás, restringindo assim o pedido dos professôres argentinos, que quiseram incluir no âmbito do Direito do Trabalho não só o trabalho subordinado, como também o trabalho prestado ao Estado e o trabalho autônomo, objetos do Direito Civil e do Direito Administrativo, respectivamente.

Por fim, permite V. Excia. mais um esclarecimento?

O SR. SALOMÃO WEINBERG - Pois não.

O SR. MARIO SEIXAS AURVALLE - O contrato de trabalho pode se definir como todo aquêle que tem por objeto o trabalho que uma pessoa física presta a outra pessoa, física ou jurídica, mediante remuneração, ficando a primeira subordinada à segunda.

De maneira que existem três elementos primordiais: a não eventualidade, a subordinação e a dependência econômica.

Nos contratos de serviços domésticos se encontram êstes mesmos elementos, apenas a "Consolidação das Leis de Trabalho" que vigora no Brasil, entende de excluir, e o faz expressamente, no art. ${ }^{\circ} 7^{\circ}$, os empregados em serviços domésticos. Isto, porém, não quer dizer que entendamos que êles não sejam empregados subordinados.

Antes da "Consolidação das Leis de Trabalho", houve um decreto - o decreto $\mathrm{n}^{\mathrm{O}} 3078$, do ano de 1941 - que considerava os domésticos como empregados subordinados e, portanto, atingidos por nosso Direito do Trabalho. Esse decreto, porém, não foi regulamentado, sendo por isso, hoje, objeto de discussão por parte dos juristas, se está ou não em vigor. Somos dos que entendem não estar em vigor, razão pela quál propugnamos para que êste Congresso, considerando que o Direito do Trabalho deva reger as normas de todo trabalho subordinado, sugira que abranja, também, o trabalho dos servidores domésticos.

O SR. SALOMÃO WEINBERG - Evidentemente, estas caracrerísticas, que são necessárias para o contrato de trabalho, também se encontram no servidor doméstico e no locador dêste serviço; entretanto, a diferença não reside na falta de elementos, mas na exis- 

tência de outros elementos que, no contrato normal de trabalho, não
existem.

O SR. CAMILO MARTINS COSTA - A especificidade do meio onde êle atua.

O SR. SALOMÃO WEINBERG - Exatamente, a comunhão, a intimidade com que o servidor doméstico penetra no lar do seu locador.

Este é um dos elementos.

O SR. CAMILO MARTINS COSTA - Poder-se-ia conceber que, mesmo do domínio do Direito Trabalhista, se trace disposição especialíssima, concernente a esta modalidade de trabalho doméstico. Específica em razão do ambiente em que trabalha e da falta de fins econômicos. Como há pouco foi dito, o patrão não tem fins econômicos; ainda, por êste lado, a situação jurídica se extrema das outras relações jurídicas que estão no domínio amplo do Direito do Trabalho.

Razão deve ter tido o legislador quando excluia, já tendo até aberto a porta do Direito Trabalhista, as relações de patrão e empregado na vida doméstica. Depois de as ter aberto, tornou a fechar as portas, evidentemente por motivos que se relacionam com a natureza da família.

E’ muito respeitável a proteção ao trabalhador, onde quer que êle esteja trabalhando, mas não menos respeitável é o ambiente da vida doméstica, em âmbito familial, em que se desenvolvem aquelas relações de trabalho.

O SR. SALOMÃO WEINBERG - Aliás, minha restrição não impede que, no momento oportuno, se estude a inclusão ou não da atividade dos domésticos no Direito do Trabalho, no Direito Civil ou em qualquer outra categoria de direito. Mas parece-me que, de momento, o Congresso não pode adotar essa conclusão, sem um estudo mais acurado e sem que a experiência trabalhista, muito recente ainda em nosso país, amadureça, para que possamos ter uma visão mais exata de como definir o contrato existente entre o empregado doméstico e o locador, que nem se quer pode se considerar um "patrado" nomestico e o locador, que nem se quer pode

O SR. PAULO BARBOSA LESSA - Sr. Presidente. V. Excia. vai me permitir que faça uma sugestão que, parece, pode harmonizar os dois pontos de vista, aparentemente divergentes. A mim parece que a proposta sustentada pela Comissão e tão bem apresentada pelo Dr. Mario Seixas Aurvalle, não colide com a proposição da tese, nem com os reparos que aqui foram feitos pelos ilustrados colegas que se colocaram numa posição aparentemente diversa.

O que se pretende com esta proposição da Comissão é só a inclusão desta relação de emprêgo doméstico no Direito do Trabalho, mas não precisamente na Consolidação das Leis do Trabalho. E' uma tese de sentido geral, e teórico e, evidentemente, no se incluir essa relação tôda específica do contrato de emprêgo doméstico, terá a mesma que sofrer as restrições que o próprio meio e a própria natureza da relação impõem.

Não se poderá. regular da mesma forma o trabalho doméstico e o trabalho numa fábrica, mas não quer isso dizer que não se possam englobar, dentro do mesmo campo do Direito do Trabalho, as duas relações.

O SR. CAMILO MARTINS COSTA - Mas o fato de englobar faz perceber uma tendência para a equiparação. Por que não se englobou o nosso trabalho de profissionais liberais? Também é trabalho e não encontramos razôes óbvias para não inclúi-lo. De certo modo, é também trabalho.

O SR. MARIO SEIXAS AURVALLE - Vou me permitir informar a V. Excia. que não é possível incluir a atividade do profissional liberal no campo do Direito do Trabalho, porque é autônomo e não subordinado.

O SR. CAMILO MARTINS COSTA - Perdão. Eu senti isso. Sei que há características diferentes, mas queria com isso fazer perceber que há, por um lado, características de outra natureza em relação ao trabalho que se opera na vida doméstica. Em nome destas características tão acentuadas, já o nosso trabalho de profissionais liberais não é o chamado trabalho dos econômicamente fracos e que por isso não pode ombrear com os locatários, a fim de estabelecer condições de serviço. Por isso, não está o nosso trabalho incluído no domínio do direito público, que é o Direito do Trabalho. Nós somos, por assim dizer, econômicamente fortes e por êste aspecto não somos incluidos no campo do Direito do Trabalho, que é direito público. Mas no trabalho doméstico se, por um lado, as características são comuns - há subordinação, há inferioridade econômica, etc. - há outra ordem de características, que nos fazem recear que a tendência seja de invadir a vida doméstica pelo direito público.

O SR. SALOMÃO WEINBERG - E será esta a tendência se fôr para o Direito do Trabalho.

O SR. MARIO SEIXAS AURVALLE - Mas a tendência é esta, porque todo trabalho subordinado deve ir para o Direito do Trabalho. Isto foi o que aprovou a Comissão. Considerando que o trabalho doméstico é um trabalho subordinado, entendeu a Comissão que êle deve ser regulado pelo Direito do Trabalho, mas não dentro das mesmas normas da Consolidação e, sim, por uma lei diferente, que venha dar outro aspecto à questão, não tão rígido.

Assim também não se compreenderá que aos trabalhádores rurais se possa estender a mesma legislação que temos para os operários da cidade, devido à distância, às dificuldades de aplicação etc. 
Mas, de qualquer maneira, a tendência é mesmo de incluir no Direito do Trabalho, todo trabalhador subordinado.

Eis a tese que me permito sustentar perante êste Congresso e que mereceu o apoio da douta Comissão, para a qual foi distribuída. (palmas).

O SR. PRESIDENTE - Vamos, então, passar à votação. Os srs. Congressistas que estiverem de acôrdo com o parecer da Comissão queiram ficar sentados. (Pausa).

O SR. CAMILO MARTINS COSTA - A minha restrição, não sei como V. Excia. interpreta; parece que envolve mesmo uma oposição às conclusões do brilhante parecer. Assim, eu voto contra o mesmo.

O SR. PRESIDENTE - Eu solicito que os que discordam do parecer queiram levantar-se. (Pausa).

Está aprovado por 9 votos contra 5. Registrem-se especialmente as observações do dr. Camilo Martins Costa e o dr. Salomão Weinberg.

O SR. MARIO SEIXAS AURVALLE - (depois de haver sido discutida uma outra tese). Peço a palavra, sr. Presidente.

O SR. PRESIDENTE - Tem a palavra o nobre congressista.

O SR. MARIO SEIXAS AURVALLE - Sr. Presidente.

Há poucos momentos, fiz eu o relatório e emiti o parecer sôbre duas teses de eminentes professôres argentinos. Talvez em virtude dos debates judiciosos dos ilustres colegas, que recebi como uma lição magnífica, por um esquecimento, coisa muito natural, V. Excia. submeteu a votos apenas um dos trabalhos. Em face disso, peço a V. Excia. colocar em votação o segundo trabalho.

Antes, porém, tomo a liberdade de recordar que a tese que $V$. Excia. deve pôr em votação propõe a substituição da expressão "direito trabalhista" por "direito laboral". O parecer é no sentido de que esta modificação não deve ser aceita, como desejam os professôres argentinos. Esta é a conclusão do relatório, brilhante, do prof. Mozart Victor Russomano, que me coube apresentar no plenário, na ausência do seu autor. $O$ prof. Russomano entende devemos continuar com expressão "direito do trabalho", porque "direito laboral" seria estrangeirismo e mesmo porque há muitos autores, como diversos espanhóis por exemplo, que consideram "direito laboral" e "direito do trabalho" como expressões equipolentes.

O SR. PRESIDENTE - Atendendo ao pedido do nobre congressista, irei pôr em votação o parecer da Comissão acêrca do trabalho do prof. Ruprecht, sôbre uma denominação mais pròpria para o Direito do Trabalho.

Está em votação. Se não houver objeções, irei considerá-lo aprovado. (pausa). Aprovado.

\section{INDICAÇÕES SÔBRE DIREITO TRABALHISTA}

\section{Félix Manuel Woelflin e Alfredo J. Ruprecht}

Professôres Catedráticos da Universidade de Rosário - República Argentina

POR CUANTO:

- El trabajo - como atividad humana - es un sólo hecho, sean cuales fueren las modalidades en que se preste, sin haber razón valedera para que se encuentre regido por normas pertenecientes a distintas ramas del derecho, cuyos principios y fundamentos son distintos entre sí.

-Que aún actualmente se considera - en froma errónea al trabajo autónomo, como regido por el derecho civil, y al subordinado bajo dependencia del Estado, por normas del derecho administrativo, excluyéndoselos del derecho laboral, en perjuicio de la autonomía del mismo.

- Que esta disperción de normas referentes a un mismo hecho, atenta contra la claridad y unidad del derecho.

POR ELLO, EL CONGRESO JURIDICO CONMEMORATIVO DEL CINCUENTENARIO DE LA FUNDACION DE LA FACULTAD DE DERECHO DE PUERTO ALEGRE, DE LA UNIVERSIDAD DE RIO GRANDE DEL SUD, DECLARA:

Oue toda relación juridica emregente del trabajo como actividad humana, debe estar regida por normas del Derecho Laboral.

\section{RELATÔRIO E PARECER}

Relator: MARIO SEIXAS AURVALLE

1 - Alfredo Ruprecht e Felix Manuel Woelflin, professôres da Universidade de Rosário, República Argentina, apresentaram um trabalho, pedindo que o Congresso declare:

10 - R. D. $-30^{\circ}$ Vol. 
"OUE TÔDA A RELAC̃̃O JURÍDICA EMERGEN"TE DO TRABALHO COMO ATIVIDADE HUMANA, "DEVE SER REGIDA POR NORMAS DE DIREITO "DO TRABALHO".

2 - Na verdade, há três tipos de trabalho humano: trabalho subordinado, trabalho autônomo e trabalho prestado ao Estado.

O primeiro é objeto do contrato individual de trabalho. O segundo é objeto do contrato de locação de serviço e de empreitada (locatio operis e locatio operarum). O terceiro é objeto do contrato. de emprêgo público.

3 - Segundo a tese sustentada pelos autores da recomendação, todos êsses três tipos de trabalho humano deverão ser regidos por normas do Direito do Trabalho.

Sem sombra de dúvida a tese apresentada merece elogios, visto. que entre os três tipos de trabalho há alusões apenas acidentais, pois sempre se trata de trabalho. Entretanto, salva reventia, ela não pode ser aceita pelo Congresso, ao menos da maneira como foi sugerida, por isso que, nos dias que correm, o Direito do Trabalho ainda: não está suficientemente amadurecido para regulamentar, com seus dispositivos, todos os tipos de trabalho como atividade humana. Impossível se torna dar a essa disciplina jurídica, presentemente, conceito tão amplo.

Aliás, o próprio MARROSU, em sua obra "Il Diritto del Lavoro", em que defende ardorosamente a mesma tese esposada pelos Professôres Ruprecht e Woelflin, reconhece:

"Hoje o horizonte que noção e conceito lógico des"cortinam pode parecer demasiadamente vasto; num

“amanhã não distante saberemoş ver e compreender tal "vastidão".

Convém que o Direito do Trabalho se limite, por enquanto, ao estudo das relações oriundas do contrato individual de trabalho, regendo, assim, apenas, o trabalho subordinado, em tôdas as suas manifestações. Vale dizer: deve regular até mesmo as relações entre trabalhadores domésticos e rurais e seus empregadores, embora com dispositivos próprios e consentâneos com a realidade dos fatos.

O trabalho autônomo e o trabalho prestado ao Estado devem continuar a ser disciplinados pelo Direito Civil e Direito Administrativo, respectivamente.

\section{CONCLUSÃO}

4:- À vista do exposto, opinamos que seja aceita a proposição ora relatada, com uma ligeira modificação. Com o reparo que introduzimos, o Congresso deverá declarar:
"OUE TÔDA A RELAC̃̃O JURÍDICA, ORIUN"DA DO TRABALHO SUBORDINADO, DEVE SER "REGIDA POR NORMAS DO DIREITO DO TRA. BALHO".

\section{DEBATES EM PLENÁRIO}

O SR. PRESIDENTE - Júlio César Bonnazzola - Em discussão, a indicação sôbre Direito Trabalhista, de autoria dos profs. Alfredo Ruprecht e Félix Manuel Woelflin, da Universidade de Rosário, Argentina. E' relator da matéria o dr. Mário Seixas Aurvalle, a quem concedo a palavra.

O SR. MÁRIO SEIXAS AURVALLE - Sr. Presidente. Srs. Congressistas.

Como membro da 9. ${ }^{a}$ Comissão dêste Congresso, à qual está afeta a matéria que versa sôbre Direito do Trabalho e Direito Industrial, me foi presente, para relatar, uma tese esboçada por dois ilustres juristas da Universidade de Rosário, República Argentina.

Não é pròpriamente um trabalho de fôlego, mas uma recomendação. Vou me permitir ler a VV. Excias. as recomendações dêstes professôres, vertidas naturalmente para o vernáculo.

(Lê as indicações).

Há três tipos de trabalho: o trabalho autônomo, o trabalho subordinado e o trabalho prestado ao Estado.

O trabalho autônomo é o que constitui objeto do contrato de locação de serviços ou do contrato de empreitada, a "locatio operis" e a "locatio operarum", nas suas formas primitivas.

O trabalho subordinado, ao contrário, é objeto do contrato de trabalho pròpriamente dito, contrato individual de trabalho. $\mathrm{E}^{\prime}$ uma forma evoluída da locação de serviços, onde surge hoje o vínculo da subordinação.

O trabalho prestado ao Estado é objeto do contrato de emprêgo público.

A tese esposada pelos ilustres professores de Rosário entende, que todo trabalho oriundo da atividade humana deve ser regido peli Direito do Trabalho. Significa dizer, que tanto o trabalho autônomo como o trabalho subordinado e mesmo o trabalho prestado ao Estado, devemser regulados pelas normas do Direito a que me referi.

A tese, de um modo geral, merece elogios. Acontece, entretanto, que, presentemente, o Direito do Trabalho não se encontra desenvolvido de u'a maneira plena, para poder abranger, dentro das suas normas, a regulamentação do trabalho autônomo e do trabalho prestado ao Estado. O próprio professor Marrosa, em sua obra "O Direito do Trabalho", em que se mostra ardoroso defensor da 
tese sustentada pelos ilustres juristas argentinos, entende que, hoje, ainda não há oportunidade de regular, no Direito do Trabalho, tôdas as três formas de trabalho humano. Na sua obra, êste emérițo jurista reconhece que "o horizonte e o conceito lógico que se descortina pode parecer demasiado vasto". Significa, que êle próprio, ardoroso defensor desta tese, entende que, ainda presentemente, não é possível que o Direito do Trabalho abranja e regule estas três atividades humanas.

De maneira que, na Comissão de que faço parte, tomei a liberdade de fazer pequeno reparo à conclusão dos ilustres e renomados juristas argentinos e, na proposição que êles fizeram presente ao Congresso Jurídico, me permiti acrescentar o seguinte: "que o Congresso declara que tôda relação jưrídica oriunda do trabalho subordinado deve ser regida por normas do Direito do Trabalho". Implica isso em dizer que o trabalho objeto do contrato individual, em tôda sua plenitude, é abrangido pelo Direito do Trabalho, mesmo a atividade dos trabalhadores rurais e, ainda, a dos empregados domésticos hoje reguladas apenas em parte. Os trabalhadores rurais, no Brasil, apenas têm direito a aviso prévio, a férias e contrato de trabalho. Os empregados domésticos, hoje, estão fora do nosso Direito, por isto que o decreto 3.078 , como não foi regulamentado não está mais em vigência e foi abolido em nosso meio.

De maneira, que a recomendação - que foi aprovada unanimemente na minha Comissão, e que faço presente a êste Congresso, é que, com esta modificação, êle declare que apenas o trabalho subordinado seja regido pelo Direito do Trabalho.

Era o que eu tinha a dizer a êste respeito. (Palmas).

\section{A PRESCRIÇÃO NO DIREITO DO TRABALHO}

\section{Mozart Victor Russomano}

Professor da Faculdade de Direito de Pelotas (Universidade do Rio Grande do Sul).

Juiz do Trabalho. Membro Titular da Soceidade Internacional de Direito Social.

\section{1 - O DIREITO DO TRABALHO COMO RAMO DA CIENCIA JURÍDICA.}

O Direito do Trabalho é uma ponta de lança da ciência jurídica a tocar o cerne do problema das "classes" e procurando, em nome do Estado, a solução da luta milenária que se trava entre elas, solução essa colocada numa geral conciliação dos espíritos e dos interêsses desarmados.

O desenvolvimento extraordinário do Direito do Trabalho, no século em que vivemos, resulta do ápice a que chegaram os sociólogos, os moralistas, os filósofos, os juristas e os políticos na sua preocupação muito humana de defender a massa que trabalha, que sofre, que pouco rendimento obtém e que constitui a maioria do povo.

Êsse desenvolvimento se fêz em todos os sentidos. Para explicá-lo, é preciso alinhar uma longa série de fundamentos. A religião, a ciência, a moral, a administração pública, a política e tantos outros fatôres impulsionaram o legislador, que compôs uma farta coletânea de leis em tôrno das questóes que se enovelam no debate dos vínculos criados entre empregado e empregador na prestação de servicos. A abundância de dispositivos sôbre o assunto lhe deu alto valor científico, pelo significado jurídico-social das relações humanas entre o patrão e o empregado; e didático, pelo valor que hoje tem, para o profissional do forum, uma visão plástica e exata das equacões sociais. Exigiu-se, assim, um estudo especializado do Direito do Trabalho.

A primeira idéia foi um sonho de solidariedade espontânea e desinteressada.

O homem explorado pelo homem foi o axioma vencido nas lutas políticas de vários séculos. 